\title{
CIENTO CINCUENTA AÑOS DE POLITICAS INMIGRATORIAS EN VENEZUELA
}

\author{
RICARDO TORREALBA* \\ María Matilde SuáreZ** \\ MARILUZ SCHLOETER***
}

\section{INTRODUCCIÓN}

DURANTE EL PERIODO COLONIAL Y hasta finales del siglo XVII, la política inmigratoria establecida por la Corona española en las colonias de ultramar, se caracterizó por fuertes restricciones al ingreso de extranjeros. Salyo los espafioles originarios de la península, los extranjeros procedentes de otras regiones de Europa sólo podían viajar a América después de obtener un permiso de la Corona y demostrar que eran católicos y de origen español. Además de estos obstáculos que dificultaban enormemente a la población europea el traslado a las colonias españolas, la imagen que predominaba en esas regiones era que todo hombre nacido fuera de América o España era "hereje" y "revolvedor" (Baralt 1939) por lo que para los europeos no españoles viajar a las colonias de ultramar era una empresa sin mayores alicientes.

Con todas estas restricciones, la inmigración del periodo colonial en Venezuela estuvo integrada por dos grupos claramente diferenciados: una población española, llegada al país en directa vinculación con las actividades económicas y político-administrativas de la colonia, y una población africana, traída compulsivamente para ser incorporada al sistema productivo bajo relaciones de esclavitud.

$\mathrm{Al}$ iniciarse en 1810 en Venezuela la guerra de la Independencia, la población abarcaba a unos 800000 habitantes de los cuales 12000 eran españoles y cana-

\footnotetext{
* Profesor-Investigador del Departamento de Antropología del Instituto Venezolano je Investigaciones Cientifficas (IVIC).

** Profesora-Ivestigadora del Departamento de Antropología del Instituto Venezolano de Investigaciones Científicas (IVIC).

*** Comisión Venezolana-Servicio Social Internacional.
} 
rios, 200000 blancos criollos, 120000 indios, 62000 negros esclavos y 406000 mestizos (Humboldt 1956: 85). Estas cifras revelan el carácter restrictivo de la inmigración de la época, ya que los blancos extranjeros apenas representaban el $1.5 \%$ de la población total del país.

Durante los años que duró la guerra, ingresaron extranjeros procedentes de otros países de Europa, pero éstos no pueden ser considerados inmigrantes puesto que se trataba de contingentes de soldados profesionales traídos para ser incorporados a los ejércitos en pugna. ${ }^{1}$ La inmigración multinacional sólo se inició en Venezuela después de que terminó la guerra en 1821 y una vez que fue establecida la República en $1830 .^{2}$ Sin embargo, esa migración internacional hacia el país, durante el siglo pasado y las primeras décadas de este siglo, no tuvo mayor relevancia. Fue a partir de 1945, a raíz de la Segunda Guerra Mundial, que los flujos de población extranjera comenzaron a tener aumentos significativos. El rápido crecimiento económico y la estabilidad política, alcanzados progresivamente en la década de 1960, contribuyeron a que migrantes procedentes del Caribe, de Colombia y de otros países andinos y del cono sur engrosaran aín más los contingentes migratorios hacia Venezuela. En 1970, la migración internacional alcanzó valores $\sin$ precedentes y esta tendencia, hasta el presente, se ha mantenido estable.

La magnitud alcanzada por la migración internacional en las últimas décadas suscitó recientemente el interés de las ciencias sociales por estudiar el problema en forma sistemática. En uno de los primeros trabajos Kritz (1972) analiza el impacto de la inmigración sobre la estructura social del país, destacando los factores económicos y sociales que hicieron posible el crecimiento acelerado de los flujos migratorios. Luego, Berglund y Hernández (1977) estudiaron detalladamente el movimiento inmigratorio y las normativas legales sobre inmigración en Venezuela y Vannini (1976) reseñó el aporte al país de la inmigración italiana de

1 Se tiene conocimiento de la participación de soldados italianos en el ejército patriota (Vannini, 1980). Sobre la participación inglesa se ha señalado que en 1819 ingresaron cerca de 1200 efectivos en la expedición del general James Towers English y que, en 1820, dos unidades irlandesas desembarcaron en Angostura y se unieron a la Legión Británíca del Ejército Patriota. En 1821, en la Batalla de Carabobo, que significó la derrota definitiva de] ejército español, se cuenta una nómina de 543 soldados y oficiales británicos, irlandeses y alemanes que conformaban el Batallón Carabobo, nombre que recibió la Legión Británica (Lambert, 1974). lgualmente, el ejército español que desembarcó en Venezuela en 1815 al mando del general Domingo Monteverde, estaba integrado por oficiales y soldados espanioles y de otras nacionalidades europeas (Baralt, 1939).

2 Entre 1821 y 1830 Venezuela formó parte, junto con Colombia, de la unidad políticoterritorial conocida como "Gran Colombia". Durante esos años Venezuela estuvo sometida a la ley de inmigración de la Gran Colombia, dictada por el Congreso Colombiano y por las leyes de 1821 y 1824 sobre confiscación de bienes, acciones y derechos de los súbditos del rey de España (Gil Fortoul, 1967). A esta época se remonta la primera colonia extranjera establecida en e] territorio nacional y de la cual se tiene conocimiento por el "Caracas Diary 1835-1840" del cónsul británico en Colombia, Sir Robert Ker Porter. Según este diario, el 2 de diciembre de 1825 arribaron a La Guaira 200 colonos escoceses contratados por la "Colombian Agricultural Society" de Londrcs para establecer una colonia en tierras pertenecientes a los "Srs. Powles, Haring \& Co." (Hacienda "El Topo"). Los colonos quedaron abandonados a su suerte y nunca recibieron las tierras of recidas, siendo necesarias colectas públicas para su sostenimiento. Para abril de 1827 sólo quedaban 127 inmigrantes y en agosto del mismo año, el último grupo de $\mathbf{5 4}$ individuos fue embarcado con destino a Estados Unidos (Dupuoy, 1973). 
las décadas de 1940 y 1950 . El análisis cuantitativo de la inmigración hacia Venezuela fue realizado por Chen y Pícouet (1980), mientras que Sassen-Koob (1980) estudió la inmigración de los años setenta destacando las condiciones de ese momento.

Todos estos trabajos, con una marcada orientación demográfica, proporcionaron una visión general de los aspectos cuantitativos y cualitativos de la migración internacional hacia Venezuela. Pero hubo también algunas contribuciones en las que el problema fue tratado en forma específica. Antequera (1980) hizo un análisis de la legislación existente sobre inmigración y Zawisza (1980) efectuó una reconstrucción de los esfuerzos inmigratorios que realizó el gobierno durante el siglo pasado, a la vez que describió, asumiendo una perspectiva arquitectónica, el problema de la vivienda en la "Colonia Tovar", la más antigua colonia formada en Venezuela por inmigrantes alemanes.

Recientemente Vessuri (1982) analizó para Venezuela el aporte de la inmigración argentina en el proceso de transferencia de conocimiento científico y tecnológico entre países de la región, y Schloeter, Suárez y Torrealba (1982), al analizar la selectividad de la migración laboral procedente de los países del cono sur en SIDOR - la mayor empresa siderúrgica del Estado venezonano- realizaron una revisión preliminar de las políticas inmigratorias en Venezuela.

Es de notar, entonces, que el estudio de las migraciones internacionales en el país apenas está comenzando y uno de los aspectos que mayor interés sugiere es el problema de las políticas inmigratorias. Estas constituyen un marco de referencia general que vale la pena profundizar para conocer mejor cuáles son las tendencias actuales de la migración y poder además ubicar en su debido contexto el estudio de problemas específicos. En este trabajo vamos, entonces, a describir las políticas de mayor relevancia que durante 150 años de vida republicana ha formulado el Estado venezolano en materia de inmigración. Estas políticas serán además contrastadas con evidencias demográficas. Ese contraste, entre intención política y realidad demográfica, permitió delimitar cuatro etapas históricas que dan muestra de las distintas orientaciones que el Estado imprimió durante todos esos años a la formulación política en lo que concernía a las migraciones internacionales. La delimitación de esas cuatro etapas ha permitido, además, describir la dinámica demográfica de las migraciones internacionales en el pasado y poder, por tanto, comprender mejor cómo son las tendencias del presente. Una primera etapa fue caracterizada como de inmigración frustrada (1830-1900), ésta estuvo seguida de una etapa de transición (1900-1936), luego tuvo lugar una tercera etapa de puertas abiertas (1936-1960) y, finalmente, se ha venido desarrollando una etapa de inmigración selectiva: 1960-1980, actualmente en plena vigencia. Cada una de estas fue objeto de una explicación sociohistórica tomando en cuenta los cambios introducidos en el comportamiento demográfico del país por la expansión del sistema capitalista.

\section{LA INMIGRACIÓN FRUSTRADA: 1830-1900}

Entre 1830 y 1900 los gobiernos venezolanos pretendieron hacer frente al subpoblamiento y a la insuficiente oferta de mano de obra agraria, estimulando la 
inmigración. Esta era considerada, además, un elemento altamente "civilizador" y "colonizador":

Inmigración... Esta es a los ojos del gobierno la gran necesidad de Venezuela... No tenemos caminos por falta de hombres; no tenemos navegación por esa misma falta; $y$ por ella es pobre nuestra agricultura, corto el cornercio, poca la industria, escasa la ilustración, débil la moral y pequeña Venezuela. Todo debemos esperarlo de la población; y hablaré de ella cuanto me sea dable, porque bajo la zona tórrida, al ver la fecundidad prodigiosa de nuestra tierra, los muchos y poderosos elementos de prosperidad que encierra y al compararlos con su estado de infancia y debilidad, nada creo más necesario ni más digno de la atención del soberano que poblarla. [Gil Fortoul 1967, (II): 90]. ${ }^{3}$

La intención pobladora del Estado se hizo patente con la promulgación de la Ley de 1831 . Esta ley que promovía la inmigración de las Islas Canarias, contemplaba conceder a todo inmigrante originario de estas islas, la "carta de naturaleza", la excepción del servicio militar y del pago de impuestos durante los primeros diez años de residencia, y el título de propiedad sobre las tierras baldías que pudiera cultivar.

En 1837, la Ley de 1831 fue reformada para hacerla extensiva a los "inmigrantes de Europa"; además, el gobierno trató de alentar la iniciativa privada ofreciendo a particulares el pago de treinta pesos por cada inmigrante que trajeran al país. Esta medida era complementada con el ofrecimiento de tierras baldías y con una disposición que contemplaba la elaboración de un "Registro de Inmigrantes" [Gil Fortoul 1967, (II): 90 y 91 ].

En 1840, una nueva reforma a la ley facultó al gobierno para estimular y proteger las empresas privadas de inmigración y se autorizó la formación de colonias de extranjeros, a las que se garantizaba el ejercicio de la libertad religiosa (González Guinand 1954). Al mismo tiempo, fue creada la Sección de Inmigración de la Secretaría del Interior y de Justicia, y fue solicitado un informe detallado a los gobernadores sobre las disponibilidades de tierra en sus respectivas provincias para asignarlas a los inmigrantes. El territorio nacional quedó dividido en tres distritos inmigratorios: Oriente, Centro y Occidente ${ }^{4}$ con sus respectivas Juntas Promotoras en las ciudades de Cumaná, Caracas y Maracaibo (Brito FigueIoa 1973).

E1 Estado venezolano trataba con todas estas iniciativas de crear una base legal y mecanismos de estímulo para incentivar la inmigración, y poder cubrir la necesidad política de poblar el territorio con miras a la colonización agrícola.

Sin embargo, los intentos por incrementar el flujo de inmigrantes por parte del gobierno no tuvieron la repercusión demográfica deseada. ${ }^{5}$ Entre 1830 y

3 Memoria del secretario del Interior y de Justicia al Congreso de la República, 1831. Citado por Gil Fort oul [1967, (II): 90 ].

4 El distrito oriental cstaba integrado por las provincias de Guayana, Cumaná, Margarita y Barcelona; el central por las provincias de Carabobo, Barquisimeto, Apure y Barinas y el occidental por Coro, Maracaibo, Mérida y Trujillo. Posteriormente se formó un cuarto distrito con las provincias de Carabobo, Barinas y Barquisimeto (Zawisza, 1980).

5 En 1844 se registró el ingreso de 86 familias alcmanas destinadas a concretar las gestiones iniciadas en 1840 por Martín Tovar para la creación de la "Colonia Tovar", la única acción colonizadora đe carácter permanente en el país. Esc mismo año el gobierno nacional 
1845 ingresaron al país 11851 inmigrantes (Tabla 1), lo que representó un promedio anual de apenas 1077 entradas.

\section{Tabla 1}

\begin{tabular}{|c|c|c|c|}
\hline \multicolumn{4}{|c|}{ MJGRACIÓN INTERNACIONAL HACIA VENEZUELA, 1832-1888 * } \\
\hline$A \bar{n} o$ & Ingresos & $A \bar{n} o$ & Ingresos \\
\hline $\begin{array}{l}1832 \\
1833 \\
1834 \\
1837 \\
1839 \\
1840 \\
1841 \\
1842 \\
1843 \\
1844 \\
1845 \\
1852 \\
1856 \\
1857\end{array}$ & $\begin{array}{r}5 \\
94 \\
230 \\
51 \\
570 \\
383 \\
827 \\
3776 \\
1568 \\
2262 \\
1365 \\
223 \\
605 \\
154\end{array}$ & $\begin{array}{l}1874 \\
1875 \\
1876 \\
1877 \\
1878 \\
1879 \text { y } 1880 \\
1881 \\
1882 \\
1883 \\
1884 \\
1885 \\
1886 \\
1887 \\
1888\end{array}$ & $\begin{array}{r}3036 \\
3060 \\
5987 \\
2816 \\
- \\
508 \\
1003 \\
1952 \\
2609 \\
2844 \\
327 \\
173 \\
1151 \\
624\end{array}$ \\
\hline \multicolumn{3}{|l|}{ Total: } & 26090 \\
\hline \multicolumn{4}{|c|}{$\begin{array}{l}\text { "Los datos aquí presentados constituyen la única información disponible, Archivos y regis- } \\
\text { tros fueron saqueados y destruidos en las continuas guerras que asolaron al país durante } \\
\text { el siglo pasado. } \\
\text { FUENTE: Landaeta Rosales, Manuel: "Gran Recopilación Geográfica, Estadística e Historia } \\
\text { de Venezuela". Caracas, 1963. Tomo I: } 146 \text { y 147. }\end{array}$} \\
\hline
\end{tabular}

En 1857, comerciantes particulares contrataron con el Estado traer 3000 agricultores canarios, pero sólo llegaron 154; este pequeño grupo y 605 alemanes que habían ingresado en 1856 constituyeron las únicas entradas registradas en los veintiún años comprendidos entre 1852 y 1873 (Tabla 1). Ese fue un período de intensos enfrentamientos políticos que culminaron con la Guerra Federal (1859-1863), la guerra civil más cruenta y devastadora en la historia del pais, cuyo

firmó contratos con Andrés Anthoine, quien se comprometía a traer entre 200 y 600 españoles para formar una colonia en Palma Sola (estado Carabobo); con Carlos Castelli, responsable de la traida de 300 a 500 migrantes alemanes e italianos; con Agustín Codazzi para la traída de 60 familias alemanas y con José Manuel Alegía, quien pensaba introducir sacerdotes para las misiones (Brito Figueroa, 1973); todas estas iniciativas no fueron llevadas a cabo. En 1847 , el gobierno suscribió un contrato con los señores "Carlos Delrue y Cía., armadores y comerciantes de Dunquerque y París" quienes se comprometian a traer al pais $80000 \mathrm{inm}$ grantes suizos, belgas y alemanes sin costo alguno para el tesoro venezolano; la empresa fracasó porque la compañía Dulrue no logró reunir el número de inmigrantes prometidos (Zawisza, 1980). 
costo humano alcanzó unos 60000 muertos y 15000 heridos en una población que en 1858 alcanzó tan sólo un millón y medio de habitantes (Matthews 1977: 9).

Una vez concluida la Guerra Federal, la acción inmigratoria tomó un nuevo impulso. En 1874, el presidente A. Guzmán Blanco promulgó un Decreto promoviendo el ingreso al país de "personas propias para la agricultura, las artes y el servicio doméstico"; al mismo tiempo, se asignaba a los agentes consulares acreditados en el exterior la gestión y contratación de inmigrantes. Para el cumplimiento de esta política inmigratoria fue creada la "Dirección de Inmigración", bajo cuyo control quedaron la Junta Central de Inmigración de Caracas y tres Juntas Subalternas en La Guaira, Valencia y Puerto Cabello.

Esta política condujo igualmente a la creación en 1874 de dos colonias. Una de ellas, denominada "Colonia Guzmán Blanco", localizada en Guatopo (Estado Miranda), estuvo formada por inmigrantes franceses, italianos, españoles y agricultores venezolanos; la otra, denominada "Colonia Simón Bolívar", fue fundada en Araira (Estado Miranda) con inmigrantes franceses e italianos y con un grupo de venezolanos. Estas colonias llegaron a concentrar entre ambas una población de 1.400 habitantes y una superficie de cultivo superior a las dos mil hectáreas (Brito Figueroa $1973^{-315}$ ). Sin embargo, ya en 1896 ambas colonias presentaban marcados sintomas de declinación y terminaron luego por desaparecer. ${ }^{6}$

En 1891 y prosigujendo con el esfuerzo político realizado durante los últimos sesenta años, el gobiernu insistía en crear estímulos y leyes para favorecer la inmigración:

Algún estadista ha dicho que, en la América Meridional, gobernar es poblar... por eso insisto en pedir a vuestra sabiduría y patriotismo leyes liberales que faciliten la venida y aclimatación del elemento extranjero, que venga a poblar nuestros campos y ciudades trayendo cada cual nuevos y fecundos gérmenes de civilización... y que votéis fuertes sumas destinadas a promover, establecer y mantener la corriente civilizadora de la inmigración. .. Con leyes mezquinas . que no dan garantías al que abandona su patria para formarse una segunda en nuestro suelo, nunca será la inmigración sino una fuente de especulaciones miserables y vergonzosas, duélame el decirlo, como lo ha sido hasta ahora. (Presidencia de la República 1970 (III): 16).

Estos pronunciamientos sugerian que todos los esfuerzos oficiales y privados llevados a cabo a lo largo del siglo habían sido infructuosos. Efectivamente, los ingresos entre 1874 y 1894 alcanzaron, con un promedio anual de 1492 entradas, un total de apenas 31350 inmigrantes (Tabla 1), en su mayoría españoles y canarios. Estos resultados no eran equiparables a la persistencia e intensidad del esfuerzo político y privado por estimularla inmigración. Los flujos migratorios seguían manteniéndose apenas perceptibles, y si se comparan con los ingresos que

6 Según los informes técnicos de la época, los factores que contribuyeron a la declinación de ambas colonias fueron su aislamiento de los centros de consumo, la mala administración, las plagas de langosta que arruinaron las cosechas y las deficientes condiciones sanitarias'de la zona. La caída de los precios del café a fines del siglo pasado y los conflictos jurídicos por la tenencia de la tierra entre colonos y propietarios privados aeeleraron el proceso de declinación de estas colonias, las cuales desaparecieron definitivamente en 1904. año en que el presidente Cipriano Castro eliminó las colonias nacionales (Zawisza, 1980: 28-30). 
tuvieron a finales de siglo países como Argentina, Brasil, Canadá o Estados Unidos (Tabla 2), los ingresos de población en Venezuela habían sido mínimos. ${ }^{7}$

Varios factores permiten explicar este fracaso. En el plano internacional, y a diferencia de otros países latinoamericanos como Brasil y Argentina, ${ }^{8}$ Venezuela ocupó una posición poco importante en el sistema capitalista en expansión. La inversión británica que a fines de la década de 1880 apenas representaba el $2.5 \%$ de las inversiones totales en América Latina (González 1980: 44) no llegó a producir ningún cambio económico significativo en el país. Por su parte, el café, principal renglón de exportación, era un producto de consumo suntuario en los mercados de Europa y Norteamérica y estaba sometido a fuertes fluctuaciones de precios en el mercado internacional, con lo cual se veian disminuidas las posibilidades de acumulación del sector agrario nacional.

Tabla 2

INMIGRACIÓN EN ALGUNOS PAISES AMERICANOS, 1874-1888

\begin{tabular}{lcc}
\hline Pais & Inmigración total & Promedio anual \\
\hline Estados Unidos & 5881000 & 392066 \\
Argentina & 1036000 & 69047 \\
Canadá & 729000 & 66250 \\
Brasil & 530000 & 55335 \\
Venezuela & 26090 & 1739 \\
\hline
\end{tabular}

FUENTE: Brito Figueroa, Federico: "Historia Económica y Social de Venezuela". Caracas, 1973. Tomo I: 315.

A nivel interno, el modelo agroexportador se caracterizaba por la debilidad financiera del sector de productores rurales y por la ausencia de un proyecto político capaz de fortalecer los sectores internos dominantes y de incrementar la capacidad de negociación nacional frente al capitalismo británico. El Estado estaba obligado a recurrir continuamente el endeudamiento externo, puesto que sus limitados recursos provenían, por una parte, del sector de productores agrícolas cuyos ingresos dependían de las fluctuaciones del mercado internacional, y por la otra, de los impuestos a las importaciones para un mercado reducido y de escaso poder adquisitivo.

7 Para 1894 la población extranjera era de 44129 personas, las cuales representaban el $1.8 \%$ entre una población total estimada en 2444816 habitantes (lzard, 1970: 9-63).

8 La expansión de la frontera cafetalera en el sureste de Brasil luego de la declinación do la agricultura de base esclavista, fue factible por la inmigración masiva que recibió cl país a partir de 1880. Holloway (1977: 304) señala un total de 2785000 inmigrantes que ingresaron por el puerto de Santos entre 1886 y 1935. En Argentina, la expansión de la producción de cereales en la región de Santa Fe entre 1870 y 1895 atrajo importantes flujos migratorios, representando la población extranjera el $55.1 \%$ de la población total de la región (Gallo, 1977: 335). En ambos casos la inversión de capitales británicos contribuyó decisivamente al proceso expansivo de la economía agrícola. 
Ia imagen externa que presentaba el pais tampoco resultaba estimulante para la inmigración. Se trataba de un país pobre, regionalmente fragmentado, sin vías de comunicación, sin industrias y asolado por frecuentes epidemias; además, el goblerno reposaba en manos de caudillos enfrentados en continuas guerras, que sumjan al país en una inestabilidad social y política.

Este cuadro estructural impidió que los sectores público y privado pudieran hacer frente a la inversión financiera que requería la empresa inmigratoria. El Estado, por su debilidad fiscal no podia hacer frente a los gastos que acarreaba la inmigración; 9 para los productores agrícolas la inmigración era un medio para cubrir las necesidades de mano de obra, pero difícilmente podian pagar a los inmigrantes mucho más de lo que pagaban a los peones venezolanos, quienes, por lo demás, eran los trabajadores peor remunerados en la sociedad venezolana de la época (Lombardi 1974). Por otra parte, el estímulo oficial de ofrecer tierras para el cultivo estuvo obstaculizado, en la práctica, por la escasa información disponible sobre la delimitación de propiedades y por la falta de registro de los terrenos públicos (Matthews 1977).

Así, entre los años 1830 y 1900 , transcurrió una etapa que hemos definido como de "inmigración frustrada", puesto que ni la acción política, ni la iniciativa privada, lograron atraer la inmigración masiva que tanto se buscaba para resolver la escasez de mano de obra y el subpoblamiento del territorio.

Cuando a comienzos del siglo xx se modifica el modelo agroexportador, a raíz de la explotación petrolera, el país da inicio, como veremos ahora, a un proceso de transición que modifica el carácter y la cuantia de los flujos migratorios internacionales.

\section{LA TRANSICIÓN: 1900:1936}

A partir de 1900 y hasta 1936 ocurren en el pais hechos trascendentales que van a imprimir una nueva dimensión a las migraciones internacionales. En la primera década de este siglo comenzó la búsqueda de yacimientos de hidrocarburos por compañías inglesas y norteamericanas. En 1917 son iniciadas las exportaciones y la industria petrolera se convirtió desde entonces en el eje de la actividad económica. En 1926 el petróleo pasó a ocupar el primer lugar en las exportaciones y en 1936 relegó a la producción agrícola al convertirse en la principal fuente de ingresos del Estado venezolano (Brito Figueroa 1973). En el orden político, los continuos alzamientos de los caudillos fueron apaciguados por el férreo control hegemónico de Juan Vicente Gómez, cuyo gobierno ha sido el de mayor duración (1908-1935) en la historia política del pais.

En lo que se refiere a la inmigración, la disposición más importante fue la "Ley de Extranjeros" de 1903, con la que el gobierno facilitaba ingresos espontáneos y masivos de población extranjera. La otra disposición legal fue la promulgación de nuevas leyes de inmigración y colonización en 1912 y 1918 , con las cuales se pretendía impulsar una vez más la inmigración agrícola.

9 La Memoria del secretario del Interior y de Justicia del año 1847 señala que, entre junio de 1840 y junio de 1847 se habían destinado al fomento de la inmigración fondos por 
A pesar de estas leyes, los movimientos migratorios arrojaron saldos de escasa relevancia (Tabla 3) y los pocos inmigrantes que llegaron no venían a satisfacer las demandas de mano de obra agraria, sino los requerimientos de la naciente industria petrolera. Las empresas extranjeras radicadas en el país para la explotación de hidrocarburos trataron de satisfacer sus demandas contratando técnicos en Inglaterra y Estados Unidos, y obreros no calificados en las islas del Caribe de habla inglesa. Al definir el tipo y calificación del personal que debía ser contratado en el exterior se estaban dando intentos de inmigración selectiva por parte de las empresas petroleras recién instaladas.

En contraposición con los criterios oficiales tradicionales sobre inmigración,

Tabla 3

\begin{tabular}{lrrr}
\hline \multicolumn{4}{c}{ MOVIMIENTO MIGRATORIO INTERNACIONAL, 1905-1932 } \\
\hline Año & Entradas & Salidas & Saldo \\
\hline 1905 & 5929 & 5519 & 410 \\
1906 & 8392 & 7343 & 1094 \\
1907 & 8350 & 7438 & 912 \\
1908 & 4280 & 3979 & 301 \\
1909 & 9284 & 7063 & 2221 \\
1910 & 8273 & 7223 & 1040 \\
1911 & 9204 & 7219 & 1985 \\
1912 & 9615 & 7981 & 1634 \\
1913 & 11617 & 10708 & 909 \\
1914 & 10610 & 9742 & 868 \\
1915 & 9818 & 8770 & 1048 \\
1916 & 8596 & 7637 & 959 \\
1917 & 7857 & 7182 & 675 \\
1918 & 6153 & 5841 & 312 \\
1919 & 12433 & 12879 & -446 \\
1920 & 11178 & 11883 & -705 \\
1921 & 10086 & 9152 & 934 \\
1922 & 9709 & 8882 & 827 \\
1923 & 10707 & 11003 & -296 \\
1931 & 11033 & 11022 & 11 \\
1932 & 646 & 735 & -89 \\
\hline
\end{tabular}

FUENTE: Izard, M.: "Series Estadísticas para la Historia de Venezuela". Mérida-1970: 61-62.

un total de 176267.92 pesos. Estos fondos eran entregados a los diferentes distrito de inmigración y a los agentes privados con el compromiso de ser reintegrados al tesoro nacional. Para el 30 de junio de 1847 habían sido reintegrados 59518.78 pesos lo que equivalía a un $33.7 \%$ de la asignación total. Esto permite demostrar las escasas sumas destinadas al fomento de la inmigración y las limitadas posibilidades de recuperar las inversiones en forma de asignaciones reembolsables. 
en 1923 el gobierno expresaba criterios que sugerian selectividad y desaceleración de las migraciones:

Es preferible llevar con lentitud el acogimiento de extranjeros en calidad de inmigrados que exponer a la nación a ser invadidos por elementos no verdaderamente aptos para las labores industriales que necesitamos. [Presidencia de la República 1970, (IV): 190.]

La política inmigratoria se orientaba de acuerdo al marco legal que proporcionaba la Ley de Extranjeros de 1903 que daba puerta franca a la entrada de personas de manera indiscriminada, estimulando una inmigración masiva de carácter espontáneo, y la Ley de Inmigración y Colonización de 1918 que apoyaba la inmigración con fines agrícolas. Pero, por otra parte, en amplio contraste con la legislación vigente, la iniciativa privada y la posición oficial sugerían criterios selectivos fuertemente vinculados a la industria petrolera en vías de expansión.

Los datos demográficos para este periodo (Tabla 3) muestran un leve ascenso en los ingresos de población extranjera, pero al mismo tiempo las salidas de población alcanzaron valores considerables. Esta situación hizo que los saldos migratorios tuvieran valores $\tan$ bajos, que en algunos años alcanzaron signos negativos. Los ingresos promediaron 695 entradas por año para el período 1905 1932 y esta cifra es explicable por el carácter temporal del trabajo calificado requerido por la industria petrolera y por las condiciones políticas imperantes, las cuales propiciaban la salida al exilio de miles de ciudadanos.

Este comportamiento de la inmigración es explicable dentro del contexto de los cambios que comienza a experimentar el proceso de acumulación capitalista en el país, pues el período 1900-1936 marca el tránsito de una economía agroexportadora a una nueva modalidad productiva minero-exportadora basado en la explotación petrolera. El creciente ingreso fiscal derivado de la renta petrolera fortaleció la posición del Estado y este hecho aparece en la escena política como un factor de poder, por lo que las relaciones Estado-empresas privadas darán un nuevo sentido a las políticas inmigratorias.

La contradicción entre la legislación y la formulación de políticas inmigratorias es comprensible en el marco de la nueva estructura de poder que facilita y estimula la penetración del capital extranjero pero conservando su autonomía en las decisiones de política interna. Las empresas petroleras que comenzaron a operar en el país en términos de economía de enclave, encontraron en la Ley de Extranjeros de 1903 el instrumento legal que propició el ingreso indiscriminado de población extranjera vinculada a la explotación petrolera. Lograban, así, estas empresas cubrir sus necesidades de mano de obra y superar las limitaciones de la legislación vigente la cual estuvo diseñada, como señalamos anteriormente, para promover una colonización agrícola. Por su parte, el Estado debió hacer frente desde 1914 al surgimiento del movimiento obrero organizado y a las primeras huelgas, las cuales se iniciaron en los sectores urbanos y luego se extendieron al sector petrolero (Tennassee 1979, Godio 1980); es por esta razón que los pro. nunciamientos oficiales buscaban desacelerar la inmigración estableciendo criterios de selectividad e imponiendo al mismo tiempo férreos controles sobre la población 
extranjera radicada en el país. ${ }^{10}$ Se buscaba de esta forma neutralizar cualquier intento de desestabilización política o laboral en el que pudieran estar involucrados obreros extranjeros.

El período 1900-1936 constituye así una época de cambios económicos y so. ciales en la que se sientan las bases para el tránsito de la Venezuela agraria y rural del siglo XIX a un país urbanizado, en vías de industrialización y fuertemente vinculado al mercado capitalista mundial en el siglo $\mathrm{xx}$. Este período queda así en la historia de las políticas inmigratorias del país como una etapa de transición, entre la frustración que acarreó durante el siglo pasado el fracaso de una política inmigratoria cuyo objetivo primordial era poblar el país, y la implementación de una política de "puertas abiertas", característica de la etapa subsiguiente, en clara correspondencia con la nueva coyuntura política y económica de un país que dejaba de ser agrario para dar paso a una industrialización en vías de expansión.

\section{LA INMIGRACIÓN DE PUERTAS ABIERTAS: 1936-1960}

A partir de 1936 la economía nacional se orientó hacia la consolidación de la floreciente industria petrolera. El crecimiento del ingreso fiscal estimuló la expansión del sector de la construcción y de los servicios, mientras que la concentración del gasto público y la inversión de capitales en las principales ciudades del centro del país, a la vez que fortalecieron el mercado interno, estimularon las migraciones internas y el proceso de urbanización. Desde ese año hubo también un cambio en la orientación del gobierno ỳ se produjo en el país una apertura política, mayores libertades públicas y fueron promulgadas nuevas leyes que daban mayores estímulos a la inmigración.

Entre 1936 y 1940 fue creada una nueva fundamentación jurídica para las políticas inmigratorias, la cual ha durado hasta el presente. En 1936 fue promulgada una nueva "Ley de lnmigración y Colonización" y fue creado el "Instituto Técnico de Inmigración y Colonización" para la asistencia de los inmigrantes y la planificación y control de la colonización agrícola. Esta nueva ley conservó el espíritu de la legislación anterior en lo que a colonización se refería, puesto que contemplaba una serie de beneficios para los migrantes que ingresaban al pais para dedicarse al trabajo agrícola, pero al mismo tiempo, impedía el ingreso a extranjeros que no fueran de "raza blanca", a los "ancianos e inválidos", a "los enfermos" y a todos aquellos que "tuvieran ideas contrarias al gobierno" (Antequera, 1980).

En 1937 fue reglamentada la entrada y permanencia de extranjeros en el territorio mediante la promulgación de una nueva "Ley de Extranjeros". Junto con el impulso de esta nueva legislación, fueron creadas 14 oficinas de Investigación e Identificación de Extranjeros en las principales ciudades del país [Presidencia de la República 1970, (III): 356]. Finalmente, en 1940 fue promulgada

10 En 1918 se promulgó una "Ley sobre Adrnisión y Expulsión de Extranjeros" y ese mismo año era solicitada al Congreso Nacional la promulgación de una "Ley de Residencia" [Presidencia de la República, 1970 (TV): 102]; posteriormente, en 1933, fue dictado el Decreto Reglamentario de la Ley de Extranjeros. Estos hechos destacan la permanente preocupación del gobierno por establecer controles eficientes sobre la inmigración. 
una "Ley de Naturalización" que derogaba la Ley vigente desde el año de 1928.

Esta nueva legislación, producto del empeño oficial por impulsar la inmigración no tuvo resultados inmediatos. Entre 1936 y 1945 ingresaron 19855 personas con un promedio de 1805 ingresos anuales (Berglund y Hernández 1977: 44), cifras que en relación a las etapas migratorias anteriores daban muestra de claros incrementos en los ingresos de población extranjera, pero que continuaban siendo de escasa significación para una población total que se acercaba a los cuatro millones de habitantes. ${ }^{11}$

Al finalizar la Segunda Guerra Mundial y por la acción, entre 1945 y 1948, de la "Junta Revolucionaria de Gobierno" con la que se interrumpía la hegemonía militar en el control del Estado, en el país es inaugurada una política inmigratoria que, basada en el marco legal vigente, favorece decididamente el ingreso de extranjeros; los mensajes presidenciales de la Junta dan cuenta de los resultados de esta política al reseñar, entre 1945 y 1947, el ingreso de 17000 inmigrantes mediante directa gestión oficial y de 25000 extranjeros llegados al país por espontánea decisión. En 1948 fue registrado el ingreso de 11307 inmigrantes y la incorporación de Venezuela a la "Organización Internacional de Refugiados" como vía para atraer mayores flujos de población europea [Presidencia de la República 1970, (IV): 268-290].

En esta política de apertura a la inmigración fueron introducidos, sin embargo, ciertos criterios de selectividad y de afirmación nacionalista:

En materia inmigratoria procuró el gobierno ajustarse a los requerimientos nacionales. Los inmigrantes venían en su mayor parte de Italia, España y Portugal y algunos eran desplazados del centro de Europa, empujados por las intolerancias políticas del viejo continente y por la ruina en que los dejo la guerra... también nos empeñamos resueltamente en que no se enquistaran núcleos de emigrantes de una misma nacionalidad dentro de comunidades cerradas... Nos interesaba el inmigrante como factor de producción y como elemento poblador, en un país de atraso y escasa densidad demográfica. Pero al blanco, como tal, y al europeo en sí, nunca lo consideramos superior a] mestizo criollo... Se ponía énfasis en la selección de agricultores, pero no sólo de ellos estaba urgido el país, también se necesitaban médicos, laboratoristas, obreros calificados, etc. y contra la tesis agrarista miope de quienes sólo consideraban útiles a los extranjeros cultivadores de la tierra, se aplicó un criterio selectivo menos excluyente, cuyos resultados beneficiosos se hicieron sentir de inmediato. (Betancourt 1969: 526-528.)

De esta forma, la Junta Revolucionaria de Gobierno logró que el proceso de inmigración hacia Venezuela tuviera unos resultados que superaban ampliamente en términos demográficos los ingresos en las etapas anteriores. En el plano internacional, la crisis económica y social posterior a la Segunda Guerra Mundial dio

11 Los bajos valores de la inmigración en este lapso pueden ser explicados en parte por las restricciones establecidas a la corriente inmigratoria que se produjo a raíz de la Guerra Civil Española. Estas restricciones se orientaron esencialmente a evitar el ingreso de personas con ideas comunistas (Mármora, 1981). Las limitaciones en el transporte aéreo y la navegación durante la guerra contribuyeron igualmente a mantener bajos los flujos migratorios procedentes de Europa. 
origen a flujos masivos de población migrante que provenían de Europa y se dirigian a los países americanos, y esta coyuntura coincidió en el plano interno. con un mayor ingreso fiscal por parte del Estado venezolano, ${ }^{12}$ el cual pudo entonces contar con mayores recursos para impulsar el proceso de captación y ayuda de la población inmigrante.

A partir de 1949 y hasta 1958, la Junta Militar que asumió la conducción del gobierno mantuvo la política de inmigración de puertas abiertas impulsada por la Junta Revolucionaria, aunque introduciendo variantes en lo que se refería a la ayuda y protección del inmigrante. Desde ese momento se redujo la participación de los organismos de inmigración y colonización y se trató de promover la inmigración mediante el otorgamiento de "Visas de Transeúnte.". En 1946, el $43.1 \%$ de las visas otorgadas correspondían a inmigrantes y el $13.7 \%$ a transeúntes; en 1958 estos valores se habían invertido y sólo hubo un $12 \%$ de visas de inmigrante, mientras que las visas de transeúnte ascendieron a un $63.2 \%$. Simultáneamente, las visas de residentes bajaban para los mismos años de $37.5 \%$ a un 17.2\% (Berglund y Hernández 1977: 56).

En 1954 los requerimientos para adquirir una visa de transeúnte se reducían a lo siguiente: ser menor, de 35 años, gozar de buena salud y tener buena conducta. Estas facilidades de ingreso se reflejaron en los valores demográficos, al producirse saldos migratorios que alcanzaron sus mayores valores entre 1953 y 1957 (Tabla 4).

De esta forma, el gobierno reorientaba lo que habían sido las formas de ingreso al pais desde comienzos de siglo. Por una parte, se daban facilidades extraordinarias al ingreso de extranjeros en una política inmigratoria de "puertas abiertas", favorecida por el aumento de los recursos fiscales del Estado provenientes del ingreso petrolero, y en la cual los criterios de selectividad eran apenas lineamientos generales, puesto que se solicitaba una inmigración que no fuera únicamente de agricultores sino que incluyera una mayor variedad de ocupaciones.

Por otra parte, al reducir drásticamente el otorgamiento de visas de inmigrante, el gobierno abandonaba lo que había sido una práctica tradicional de fomentar la inmigración por medio de la asistencia y protección al inmigrante. Con esta nueva orientación, los organismos responsables de programas inmigratorios se reorientaron hacia otras actividades ${ }^{13}$ y el control de extranjeros pasó a ser responsabilidad de los organismos de seguridad del Estado.

A lo largo de la década de 1950 se produjo en el país un proceso de contracción

12 Por Decreto-Ley del 31 de diciembre de 1945, la Junta Revolucionaria de Gobiemo estipuló un impuesto extraordinario a las compañáas petroleras que operaban en el país. Este impuesto significó ingresos extraordinarios que sólo en 1946 alcanzaron a Bs. 96 millones (U.S. $\$ 28$ millones). Al mismo tiempo, la producción petrolera venezolana alcanzó para 1948 un incremento de $150 \%$ con respecto a la producción del año 1938 . El ingreso petrolcro se incrementó en $621 \%$ en el lapso de diez años comprendidos entre 1938 y 1948 (Betancourt, 1969: 190-293).

13 El "Institu to Agrario Nacional" (1AN) sustituyó en 1949 al "Instituto Técnico de Inmigración y Colonización". El IAN en ningún momento contó con los instrumentos necesarios para implementar programas de inmigración y colonización y su acción sc orientó hacia la asistencia técnica de inmigrantes establecidos en las zonas rurales. A partir de 1961 sus actividades fueron reorientadas llegando a ser uno de los principales organismos de ejecución de la reforma agraria promulgada en ese año. 


\begin{tabular}{|c|c|c|c|}
\hline \multicolumn{4}{|c|}{ Tabla 4} \\
\hline \multicolumn{4}{|c|}{ MOVIMIENTO MIGRATORIO DE EXTRANJEROS, 1948-1961 } \\
\hline$A \tilde{n} \dot{o}$ & Entrada & Salidas & Saldo \\
\hline $\begin{array}{l}1948 \\
1949 \\
1950 \\
1951 \\
1952 \\
1953 \\
1954 \\
1955 \\
1956 \\
1957 \\
1958 \\
1959 \\
1960 \\
1961\end{array}$ & $\begin{array}{r}71168 \\
72 \quad 902 \\
79 \quad 050 \\
74833 \\
85240 \\
102676 \\
113459 \\
137416 \\
136216 \\
150361 \\
138835 \\
141079 \\
127567 \\
110322\end{array}$ & $\begin{array}{r}34164 \\
46498 \\
51682 \\
50826 \\
56562 \\
50599 \\
67623 \\
79874 \\
91436 \\
104305 \\
122970 \\
124233 \\
127946 \\
111156\end{array}$ & $\begin{array}{r}37004 \\
26404 \\
27368 \\
24007 \\
28678 \\
42007 \\
45336 \\
57542 \\
44780 \\
46056 \\
15865 \\
16846 \\
-379 \\
-834\end{array}$ \\
\hline
\end{tabular}

FUENTE: Berglund, S. y Hernández, H. "Estudio Analítico de la Política Inmigratoria en Venezuela". Caracas, 1977: 51.

económica y una desestabilización política que culminó con el derrocamiento del gobierno militar en 1958. Las erráticas políticas económicas y sociales durante la década hicieron insostenible el financiamiento de los planes de construcción del gobierno $\mathrm{y}$, pese al rápido crecimiento industrial, las tasas de desempleo aumentaron aceleradamente pasando de un $6.3 \%$ en 1950 a $13.1 \%$ en 1961 (Aranda 1977: 172). El régimen democrático que asumió el poder en 1958 buscó frenar el desempleo mediante el cierre drástico de la inmigración. A partir de ese momento los flujos migratorios comenzaron a declinar y la etapa de "puertas abiertas" culimina en 1960 con saldos negativos (Tabla 4). La etapa que transcurre entre 1936 y 1960 representa, por primera vez en la historia del país, un periodo en el que la respuesta demográfica coincide con las expectativas oficiales de captación de población migrante.

La economía venezolana durante esos años, se orientó a la consolidación de la industria petrolera y a la expansión de la economía urbana. La acción estatal se concentró principalmente en Caracas y las principales ciudades del centro del pais impulsando una infraestructura vial, habitacional y de servicios que contribuyó al fortalecimiento de esa economía urbana. La industria petrolera, la construcción, el comercio y los servicios constituyeron el eje del proceso de acumulación, cuyo asiento fundamental fueron las ciudades. A partir de 1950 , fue iniciado además un proceso de industrialización basado en la sustitución de importaciones alrededor de la capital y de las principales ciudades del centro del país; como esto fue un importante estímulo a las migraciones internas los sectores urbanos se fortalecieron aún más. El Estado dispuso de mejores recursos económicos para hacer 
frente a la captación de inmigrantes, y como las actividades del agro pasaron a un segundo plano las necesidades de mano de obra se circunscribieron a los sectores urbanos.

En el aspecto internacional, la crisis de posguerra estimuló movimientos masivos de población europea hacia Estados Unidos y algunos países latinoamericanos, entre ellos Venezuela. Este hecho condujo a que los migrantes y refugiados que recibió el país cubrieran una amplia gama de oficios y profesiones, y que éstos se establecieran principalmente en las zonas urbanas y trabajaran en sectores, como el de la construcción, cuya demanda de mano de obra era mayor.

Al concluir la década de 1950 el país presentaba una nueva imagen debido al carácter urbano e industrializado de su proceso de crecimiento económico, por lo que ahora sí era un territorio atractivo para la inmigración. Pasado el auge inicial de la expansión industrial fue necesario introducir los ajustes que el modelo económico requería, y al hacer frente al problema del desempleo, el gobierno debió cancelar la política inmigratoria de "puertas abiertas" protegiendo la mano de obra nacional. En la etapa siguiente, a partir de 1960, el carácter y cantidad de los flujos migratorios estuvieron regidos por criterios de selectividad los cuales por primera vez en la historia de las migraciones venezolanas se iban a hacer definitivamente explícitos.

\section{LA INMIGRACIÓN SELECTIVA: $1960-1980$}

La década de 1960 corresponde a la instauración en el país de la democracia representativa, y en su comienzo el nuevo gobierno democrático debió enfrentar una recesión económica y altas tasas de desempleo. Desde 1958 se habían venido estableciendo fuertes restricciones a la inmigración y el otorgamiento de visas sólo era posible para fines de reagrupación familiar y para trabajadores calificados en aquellas actividades donde la oferta de mano de obra nacional era insuficiente.

El ordenamiento jurídico no sufrió modificaciones, salvo la promulgación en 1966 de una nueva "Ley de Inmigración y Colonización" que conservó el texto de la Ley de 1936, pero que eliminó las restricciones de raza. ${ }^{14} \mathrm{En}$ ęse mismo año fue creado el "Departamento de Migración Selectiva" dentro de la Dirección de Economía y Empleo del Ministerio del Trabajo; este departamento constituyó el primer esfuerzo oficial para delinear una política inmigratoria basada en la selectividad.

Los criterios de selectividad que iban a orientar la politica immigratoria estaban reflejados en la posición del nuevo gobierno:

14 La "Ley de Inmigración y Colonización" de 1966 centraba su acción en el estímulo a la inmigración con fines de colonización agrícola. Este interés es evidente cuando adscribe al Ministerio de Agricultura y Cría "todos los servicios relacionados con la inmigración y la colonización" (Ley de Inmigración y Colonización, 1966, artículo $2^{\circ}$ ). Si bien el artículo 34 menciona que se podrán fundar colonias industriales, ni en la propia ley, ni en normativas anteriores como el "Reglamento General de Colonias" de 1949, ni en normativas posteriores, se reglamenta el funcionamiento de las colonias industriales, siendo ésta una idea que nunca fue llevada a la práctica. 
El proceso de industrialización y de reforma agraria deberá proveer de suficientes oportunidades de trabajo no sólo para dar ocupación a los nuevos contingentes que se ofrecen al mercado de trabajo sino también para ir disminuyendo el subempleo crónico. Para facilitar este proceso se impulsará la capacidad de la mano de obra y sólo en forma selectiva y limitada se acudirá a la inmigración para reforzar los cuadros técnicos. [Presidencia de la República $1970,($ IV): 36 .]

Los valores demográficos entre 1960 y 1970 son una clara respuesta a esta nueva orientación de las políticas inmigratorias: durante ese lapso el saldo migrato. rio fue de 2350 personas, con un promedio de 213 personas por año (Mármora 1981: 51) lo que supone una drástica disminución de los ingresos de extranjeros. Sin embargo, durante el período se producen importantes cambios en la compo. sición de la inmigración hacia Venezuela: el ingreso de población procedente de Portugal tiende a crecer, en tanto que la inmigración colombiana se incrementa considerablemente alcanzando un saldo positivo de 55288 personas, con un promedio anual de 5026 ingresos. Por su parte, los españoles e italianos presentan valores de emigración del orden de 1561 y 33053 (Tabla 5).

\begin{tabular}{|c|c|c|c|c|c|}
\hline \multicolumn{6}{|c|}{ Tabla 5} \\
\hline \multicolumn{6}{|c|}{$\begin{array}{c}\text { SALDOS MIGRATORIOS DE EXTRANJEROS POR NACIONALIDADES, } \\
1948-1959\end{array}$} \\
\hline$A \tilde{n ̃ o}$ & Total & Colombianos & Españoles & Italianos & Portugueses \\
\hline $\begin{array}{l}1948 \\
1949 \\
1950 \\
1951 \\
1952 \\
1953 \\
1954 \\
1955 \\
1956 \\
1957 \\
1958 \\
1959\end{array}$ & $\begin{array}{ll}37 & 004 \\
26 & 101 \\
27 & 421 \\
24 & 011 \\
28 & 918 \\
42 & 080 \\
45 & 861 \\
57 & 542 \\
41 & 780 \\
46 & 056 \\
15 & 865 \\
16 & 847\end{array}$ & $\begin{array}{ll} & * \\
& * \\
& * \\
3 & 804 \\
7 & 137 \\
5 & 390 \\
3 & 452 \\
3 & 076 \\
3 & 836 \\
5 & 061 \\
4 & 027 \\
2 & 791\end{array}$ & 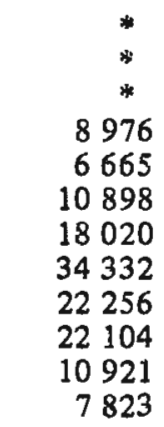 & $\begin{array}{rl}* & * \\
* & * \\
6 & 998 \\
12 & 099 \\
17 & 992 \\
12 & 963 \\
18 & 126 \\
9 & 046 \\
6 & 045 \\
-5 & 930 \\
4 & 471\end{array}$ & $\begin{array}{l}* \\
* \\
* \\
1101 \\
615 \\
4305 \\
6316 \\
5911 \\
2829 \\
3394 \\
2400 \\
2716\end{array}$ \\
\hline Total & 409486 & 38574 & 131995 & 81810 & 29587 \\
\hline
\end{tabular}

* Información no disponible

FUENTE: Oficina Central de Estadística e Informática. Citado por Lelio Mármora: "Las Migraciones Laborales Internacionales en Venezuela". Quito 1981. pág. 33.

Al mismo tiempo, la insuficiencia de mano de obra rural producida por las migraciones internas fue suplida, a pesar de la política de selectividad, por trabajadores colombianos que ingresaron al pais de manera ilegal. Se estima que el número de estos ingresos durante la décadá alcanzó el millón de indocumenta- 
dos, de los cuales permanecían en el país hacia 1970 aproximadamente medio millón (Sassen-koob 1980: 67).

Este comportamiento de la inmigración durante la década de 1960 puede ser explicado por causas internas y externas. En el plano interno, la contracción económica y las altas tasas de desempleo estimularon la aplicación de restricciones a la inmigración, buscando de esta forma proteger la mano de obra nacional y evitar el desplazamiento de trabajadores nacionales por inmigrantes. En el plano internacional, el proceso de reconstrucción de Europa a través del "Plan Marshall" para fines de la década de 1950 había dado los resultados deseados. Este hecho y la expansión capitalista en Europa occidental provocaron una reducción de los flujos migratorios europeos hacia América Latina y una reorientación de los movimientos migratorios en el interior del continente. ${ }^{15}$

Al comienzo de la década de 1970 , el incremento de los precios del petróleo en el mercado internacional produjo en el país una bonanza económica sin precedentes; el ingreso fiscal se incrementó de Bs.* 16432 millones (U.S.\$ 3821 millones) en 1973, a Bs. 42834 millones (U.S.\$ 9961 millones) en 1974 y las inversiones estatales crecieron en un $300 \%$ entre 1973 y 1976 . Buena parte de esta inversión fue destinada al impulso de las industrias básicas controladas por el Estado y a la inversión reproductiva en los sectores agrícola e industrial (Presidencia de la República 1977).

El efecto multiplicador de la inversión estatal, al hacer impacto en la economía global, estimuló el crecimiento industrial impulsando una política de pleno empleo que puso en evidencia la insuficiencia de recursos humanos para los planes: de expansión económica. Esta necesidad de mano de obra calificada, compartida tanto por el sector público como por el privado, se tradujo en un debilitamiento de las restricciones para el ingreso al país. La nueva situación estimuló dos flujos masivos de población latinoamericana: una procedente de los paises del cono sur por motivos esencialmente políticos, y otra procedente de Colombia en la cual privaron incentivos económicos. Entre 1971 y 1976 el ingreso de población colombiana se incrementó en un 113\% y el ingreso de chilenos y argentinos en más del $50 \%$. En general, todas las nacionalidades latinoamericanas mostraron crecimientos apreciables $y$, en conjunto, alcanzaron durante esos cinco años un crecimiento de $106 \%$ (Tabla 6).

La rápida expansión de la inmigración se evidencia en los valores estadísticos; mientras que para el periodo 1959-1973 el promedio anual de adquisición de residencia permanente fue de 25400 personas por año, entre 1974 y 1976 este valor se incrementó a 50000 por año. Las legalizaciones de indocumentados que

15 Entre 1946 y 1957 Europa presentó valores de emigración neta de 5.4 millones de personas; en el período 1960-1970 estos valores se redujeron a 0.3 millones de emigrantes (Lasserre-Bigorry, 1975: 3). Sin embargo, estas tasas globales encubren la nueva orientación de las corrientes migratorias: para el período 1960-1970, los países de Europa occidental (Austria, Bélgica, Francia, Luxemburgo, Holanda, Alemania Federal y Suiza) recibieron 4.9 millones de migrantes, cifra superior a la recibida por Estados Unidos en el mismo periodo (4.1 millones), mientras que el resto de países europeos (salvo Hungría, Dinamarca, Noruega y Suecia que presentaron saldos positivos poco relevantes) perdian población (LasserreBigorry, 1975: 20). De esta forma quedaban claramente definidos como polos de atracción de población los países europeos en los euales se concentró la expansión capitalista.

* Bs: Bolívar, unidad monetaria venezolana. 
Tabla 6

\begin{tabular}{|c|c|c|c|}
\hline \multicolumn{4}{|c|}{$\begin{array}{c}\text { INGRESOS REGISTRADOS PROVENIENTES DE SUDAMERICA } \\
\text { TASAS DE CRECIMIENTO 1971-1976 }\end{array}$} \\
\hline Pais & 1971 & 1976 & $\%$ de aumento \\
\hline Colombia & 87691 & 187422 & 113.7 \\
\hline Ecuador & 6609 & 11366 & 72.0 \\
\hline Perú & 3627 & 6481 & 78.7 \\
\hline Bolivia & 1741 & 2513 & 44.3 \\
\hline Chile & 4646 & 11876 & 55.6 \\
\hline Argentina & 7951 & 12111 & 52.3 \\
\hline Unguay & 1201 & 4286 & 256.9 \\
\hline Paraguay & 208 & 325 & 52.3 \\
\hline Brasil & 2214 & 3052 & 37.8 \\
\hline Total & 115.888 & 239.432 & 106.6 \\
\hline
\end{tabular}

FUENTE: Sassen-Koob, S.: “Crecimiento Económico e Inmigración en Venezuela". Caracas, 1980: 74 .

habían alcanzado un promedio anual de 3700 entre 1959 y 1973 se elevaron a 33400 por año entre 1974 y 1976 , en tanto que las deportaciones presentaban promedios anuales de 1560 y 22700 para los respectivos períodos (Sassen-Koob 1980: 77). Estas cifras demuestran que el incremento en los flujos migratorios legales e ilegales estuvo acompañado del esfuerzo oficial por controlar en alguna medida el ingreso de población indocumentada.

A partir de 1976, con la puesta en marcha del "V Plan de la Nación", el gobierno definió áreas prioritarias para el desarrollo económico entre las cuales se destacaron las industrias básicas controladas por el Estado (petróleo, petroquímica, siderúrgica y electrificación); los planes de expansión previstos para estas industrias, plantearon la necesidad de captación de mano de obra extranjera calificada para suplir la limitada oferta de mano de obra nacional, y fue así como tuvieron que ser definidos programas de inmigración selectiva.

De allí que a partir de 1976, la acción oficial se orientó a establecer estrictos controles en el ingreso de población extranjera no calificada, limitando el otorgamiento de visas de residencia y desarrollando organismos de coordinación y pla. nificación de políticas de inmigración selectiva. En este sentido, se ampliaron las funciones de control de extranjeros de la "Dirección de Identificación y Extranjería (DJEX) del Ministerio de Relaciones Interiores y se reanudó contrato, en ese mismo año, con el "Comité Intergubernamental para las Migraciones" (CIM), organismo internacional responsable de programas de inmigración selectiva.

Igualmente, el Ejecutivo Nacional creó el "Programa de Recursos Humanos" adscrito a la Oficina de Coordinación y Planificación de la Presidencia de la República" (CORDIPLAN) ${ }^{16}$ y constituyó e] "Comité Tripartito de Inmigración

16 El "Programa de Recursos Humanos" de CORDIPLAN funcionó hasta fines de 1979. 
Selectiva", ${ }^{17}$ organismo responsable del estudio y aprobación de ingreso de personal extranjero calificado. Al mismo tiempo, el 23 de junio de 1976 fue creado por Decreto Ejecutivo el "Consejo Nacional de Recursos Humanos", el cual tiene como una de sus atribuciones "formular criterios para la adecuada utilización de expertos, técnicos y mano de obra calificada provenientes de otras naciones, según las conveniencias del sistema productivo nacional" (Presidencia de la República 1976 , Decreto 1649 , artículo $3^{\circ}$ ) ${ }^{18}$ Con este conjunto de medidas, la acción oficial se orientaba definitivamente hacia una nueva racionalidad que sustentaba la selectividad de la inmigración.

Los resultados demográficos de esta nueva orientación política no fueron perceptibles de inmediato. Después de 1976, los saldos migratorios continuaron en aumento alcanzando en 1978 valores muy altos; sin embargo, en 1979, los saldos migratorios comenzaron a declinar hasta alcanzar signos negativos en 1980 (Tabla 7), reflejando la política de selectividad que el gobierno estaba tratando de imprimir a la inmigración.

Finalmente, el Ejecutivo Nacional en un intento de sincerar el delicado problema de los indocumentados, promulgó en 1980 el "Reglamento sobre Admisión y Permanencia de Extranjeros en el País", ${ }^{19}$ para normalizar la permanencia de la población extranjera en situación ilegal. De esta forma la acción oficial reciente se ha orientado en dos direcciones: por una parte, desarrollando una política de inmigración selectiva a través de organismos especialmente creados con ese fin y dejando campo abierto a la iniciativa privada para la captación y contratación de personal calificado en el exterior $y$, por la otra, tratando de establecer controles sobre el ingreso de indocumentados, legalizando la situación de los que ya están en el país y estableciendo operativos de deportación y control fronterizo destinados a evitar nuevos ingresos ilegales.

en enero de 1980 fue transferido al Ministerio del Trabajo siendo llamado a partir de ese momento "Oficina de Inmigración Selectiva".

$17 \mathrm{El}$ "Comité Tripartito de Inmigración Selectiva" está integrado por representantes del gobierno, del sector privado y de la Confederación de Trabajadores de Venezueja, la central obrera de may or importancia del país. Su función es el control y regulación de la inmigración selectiva por medio de la aprobación o rechazo de las solicitudes de ingreso de personal calificado que son presentadas por intermedio de la Oficina de Inmigración Selectivạ del Ministerio del Trabajo.

18 E1 17 de diciembre de 1979 , por Decreto Presidencial $\mathrm{N}^{\circ} 419$, fueron ampliadas las funciones del Consejo Nacional de Recursos Humanos. El nuevo decreto señala explícitamente como atribución del organismo "formular la política de inmigración selectiva de técnicos y mano de obra calificada que se requiere, según las necesidades y prioridades del desasrollo económico y social del país" (Presidencia de la República, 1979, Decreto 419, artículo $4^{\circ}$ ).

19 El "Reglamento sobre Admisión y Permanencia de Extranjeros en el País" fue promulgado con fecha 22 de mayo de 1980 mediante el Decreto Presidencial No 616 y tiene como objeto ordenar "la formación de la Matrícula General de Extranjeros, en la cual se registrarán todos los extranieros domiciliados o residenciados en el pajs, que se encuentran en éste para la fecha de publicación del presente Reglamento". La "Matrícula General de Extranjeros" se limitó a aquellos extranjeros que se encontraban en el país en situación irregular y con el objeto de legalizar su permanencia. En la "Matrícula se registraron 266795 extranjeros en situación ilegal; de éstos 246194 eran colombianos representando el $92.3 \%$ del registro total, estando localizada la mayor parte $(69.4 \%)$ en los estados limítrofes con Colombia (DIEX, 1981). 
Tabla 7

\begin{tabular}{lrrr}
\hline \multicolumn{4}{c}{ MOVIMIENTO MIGRATORIO DE EXTRANJEROS, $1970-1980$} \\
\hline Años & Entradas & Salidas & Saldo \\
\hline 1970 & 182222 & 193673 & -11451 \\
1971 & 239728 & 212930 & 26798 \\
1972 & 273423 & 262588 & 10835 \\
1973 & 394662 & 372140 & 22522 \\
1974 & 384842 & 333323 & 51519 \\
1975 & 415538 & 379317 & 36221 \\
1976 & 422298 & 407707 & 14591 \\
1977 & 606769 & 547642 & 59127 \\
1978 & 506493 & 434981 & 71512 \\
1979 & 528184 & 506674 & 21510 \\
1980 & 472345 & 487469 & -15124 \\
Total & 4426504 & 4138444 & 288060 \\
\hline
\end{tabular}

FUENTE: Oficina Central de Estadística e Informática y Dirección de Identificación y Extranjería. Citado por Enzo Lazio: "Identificación y Análisis de las Condiciones Generadoras de las Corrientes Migratorias Latinoamericanas hacia Venezuela, 1974-1979". Caracas. Consejo Nacional de Recursos Humanos. 1982. pág. 23.

Durante las décadas de 1960 y 1970 se configuró así una etapa de inmigración selectiva que perdura en el presente, en la que el carácter y composición de los flujos inmigratorios variaron drásticamente en comparación con las etapas anteriores. Este comportamiento político-demográfico resulta explicable al tomar en cuenta en primer término en el plano. interno el derrocamiento de la dictadura militar en 1958, así como la contracción económica y la presencia de altas tasas de desempleo y subempleo. Esta situación condujo a que las medidas económicas y sociales que formularon los nuevos gobiernos democráticos, fueran destinadas a la protección del empleo de los trabajadores nacionales.

Al mismo tiempo, al continuar la expansión del modelo de acumulación en torno a la economía urbana, el crecimiento de las ciudades y la migración ruralurbana se intensificaron, acentuando la presión demográfica sobre el empleo urbano. Estos hechos explican el desestimulo a la inmigración indiscriminada y los criterios de selectividad que comienzan a ser aplicados.

Igualmente, las condiciones político-económicas, la apertura democrática y el aumento de los ingresos fiscales explican los flujos masivos de población ilegal procedentes de Colombia, los cuales van a cubrir la insuficiencia de trabajadores rurales dejada por las migraciones internas y las nuevas demandas de mano de obra del sector agroindustrial en expansión.

El incremento en los precios del petróleo durante la década de 1970 contribuyó al crecimiento del modelo minero-exportador estimulando la oferta de trabajo y la inmigración; fue necesario entonces desde 1976 dotar al país 
de instrumentos adecuados para llevar adelante una inmigración selectiva y poder controlar la inmigración indiscriminada.

La coyuntura internacional proporciona elementos de juicio para entender aún mejor el desarrollo de esta etapa de inmigración selectiva. Al variar el cuadro estructural de la economia europea, luego de la reconstrucción de posguerra, la inmigración procedente de los países de Europa no sólo declinó sino que se produjeron importantes movimientos de migración de retorno. Paralelamente, la inestabilidad económica y política de los países del cono sur y la imagen de estabilidad democrática y bonanza económica que presentaba Venezuela, hicieron que el país se convirtiera en un territorio atractivo para los inmigrantes de la región latinoamericana $y$, ante el auge de los flujos migratorios internacionales, el Estado buscó controlar mecanismos de selectividad que imprimierón una nueva racionalidad a las políticas inmigratorias.

\section{CONCLUSIONES}

En este trabajo hemos efectuado una reconstrucción histórica con la que hemos descrito 150 años de políticas inmigratorias; esas políticas fueron contrastadas con los resultados demográficos correspondientes y fue posible delimitar cuatro etapas históricas en el desarrollo de la inmigración internacional en Venezuela.

Hemos podido apreciar cómo a lo largo del siglo xix existió un marcado interés privado y oficial por impulsar la inmigración al considerarla un elemento poblador y factor de productividad en la agricultura. La amplia legislación que se produjo durante esa época tendió a crear un ordenamiento legal que buscaba estimular la inmigración; sin embargo, la intención reflejada en las leyes sobre la materia y el apoyo gubernamental y privado contrastaron con los limitados resultados en cuanto a captación de población inmigrante, en una etapa de "inmigración frustrada".

Durante las primeras décadas del presente siglo, en una etapa de "transición", se produjo el paso de una economía agraria a una economía petrolera fuertemente vinculada a los mercados internacionales. Esta variación del modelo de acumulación fue acompañada de cambios cuantitativos y cualitativos en la inmigración. La tendencia inicial a traer agricultores canarios y españoles fue sustituida por el ingreso de mano de obra calificada procedente de otros países de Europa, Estados Unidos y las Antillas, para cubrir las crecientes demandas de la industria petrolera, siendo esta actividad controlada y estimulada por la inciativa privada.

Sin embargo, el decisivo impulso de la inmigración y su materialización en resultados concretos sólo se produjeron a partir de la dećada de 1940 con una política de "puertas abiertas". Esta política estuvo especialmente vinculada con la reformulación de las relaciones Estado-empresas petroleras; de esta manera tuvo lugar un incremento apreciable en los ingresos fiscales y el Estado venezolano no sólo fortaleció su posición política sino que pudo contar con los recursos necesarios para impulsar la inmigración como vía para cubrir las crecientes demandas de mano de obra generadas en la construcción y los servicios. Al mismo tiempo, la coyuntura internacional permitió que el país captara impor'nntes flujos de migrantes europeos a raiz de la crisis de posguerra. 
Al variar las condiciones coyunturales de la economía nacional hacia la década de 1960 se produjo un desestímulo oficial a la inmigración, pero a partir de 1973, con el incremento de los precios del petróleo, la mayor capacidad fiscal del Estado permitió el impulso de importantes planes de desarrollo a la vez que estimuló la expansión del sector industrial y la capacidad de generación de empleo. Estas nuevas condiciones económicas y sociales fortalecieron la imagen internacional del país y atrajeron flujos de población migrante de los países del cono sur, desestabilizados política y económicamente, y en particular acrecentaron los flujos legales e ilegales procedentes de Colombia, Centroamérica y el Caribe. Esta situación ameritó el surgimiento de una última etapa de "inmigración selectiva", actualmente en curso.

Venezuela se convirtió durante los últimos años en un país política y econó. micamente atractivo en la región latinoamericana, y los enormes flujos de migración legal e ilegal acarrearon problemas que exigieron la intervención controladora del Estado. Buena parte de la estrategia estatal para contrarrestar la inmigración desmedida fue el fomento de planes de inmigración selectiva mediante la creación de organismos especializados, suscripción de convenios internacionales y e] otorgamiento de facilidades a las empresas estatales y privadas para la contratación de fuerza laboral extranjera califícada.

E1 predominio de una determinada política inmigratoria en ciento cincuenta años de historia permitió así ubicar el proceso cumplido por la migración internacional, $y$, sobre todo, apreciar que no siempre la decisión política tuvo las repercusiones demográficas deseadas. Los grandes contingentes de inmigración coincidieron con períodos en los que el Estado incrementó su participación fiscal al lograr mejores términos de intercambio en la comercialización del petróleo.

Estos incrementos en la renta petrolera facilitaron reajustes en el modelo de acumulación y estimularon procesos de desarrollo que, al inducir una mayor oferta de mano de obra, atrajeron flujos masivos de población extranjera.

En el aspecto legal, desde 1936 tiene vigencia en Venezuela la "Ley de Inmigración y Colonización" la cual propugnó la colonización agrícola. Esta ley estuvo inspirada en el contexto rural que caracterizaba a la sociedad de ese momento. Hoy, después de casi medio siglo, las políticas del Estado tienen el mismo basamento legal, y éste, ante la multiplicidad de organismos y funciones diferentes en un país urbano y en plena expansión industrial, se ha convertido en un instrumento virtualmente inaplicable a la realidad.

En Venezuela y hasta el presente, el.proceso histórico de la inmigración constituye un buen ejemplo explicativo de los efectos del desarrollo del capitalismo al tratar de consolidar su proceso expansivo. El Estado, al asumir funciones de estímulo y regulación inmigratorias, da respuesta a las necesidades laborales que reclama la expansión del modelo económico. Los movimiento internacionales de población se presentan así, como traslados masivos de mano de obra dentro de un mercado laboral global que responde a la dinámica de crecimiento del sistema capitalista mundial y en la cual las fronteras nacionales son sólo divisiones polítjcas en un espacio único que es el espacio capitalista. 


\section{Bibliografía}

ANTEQuera, R., 1980. "Régimen Legal del Inmigrante en Venezuela" Barquisimeto. Consejo Nacional de Recursos Humanos y Universidad Centrooccidental Lisandro Alvarado.

ARANDA, S., 1977. "La Economía Venezolana". Bogotá. Siglo XXI editores.

Baralt, R. M., 1939. "Resumen de la Historia de Venezuela" Brujas-París-Declée, Brouwer.

Berglund, S., Hernández, H., 1977. "Estudio Analítico de la Política Inmigratoria en Venezuela". Caracas. Consejo Nacional de Recursos Hümanos y Ministerio de Relaciones Interiores.

Betancourt, R., 1969. "Venezuela, Política y Petróleo". Caracas. Editorial Senderos. 3a. ed.

BRITo Figueroa, F., 1973. "Historia Económica y Social de Venezuela". Caracas. Universidad Central de Venezuela. 3 tomos.

CHEN, Ch., Picouet, M., 1980. "Migración Internacional en Venezuela: Evolución y Características Socio-Demográficas". Migraciones Internacionales en las Américas. 1 (1): 41-62.

DIEX., 1981. "Matrícula General de Extranjeros", Caracas. Ministerio de Relaciones Interiores. Dirección de Identificación y Extranjería.

Dupuoy, W., 1973. "Una Efímera Colonia de Escoceses en la Venezuela del Siglo XIX", El Farol. 223:

Gallo, E., 1977. "The Cereal Boom and Changes in the Social and Political Structure of Santa Fe, Argentina, 1870-95", en Land an Labour in Latin America. Essays on the Development of Agrarian Capitalism in the Nineteenth and Twentieth Centuries. K. Duncan y I. Rutledge (eds.) Cambridge. Cambridge University Press. 323-342.

Gil Fortoul, J., 1967. "Historia Constitucional de Venezuela". Caracas Librería Piñango. 3 Tomos. 5a. ed.

Godio, J., 1980. "El Movimiento Obrero Venezolano, 1850-1944". Caracas. Editorial Ateneo de Caracas.

GonzÁlez Ginand, F., 1954. "Historia Contemporánea de Venezuela". Caracas. Ediciones de la Presidencia de la República.

González, M. E., 1980. "Los Intereses Británicos y la Política en Venezuela en las Ultimas Décadas del Siglo XIX". Caracas. Primeras Jornadas de Historia de Venezuela. Universidad Central de Venezuela. Multigrafiado.

Holloway, T. H., 1977. "The Coffee Colono of Sao Paulo, Brazil: Migration and Movility, 1880-1930" en Land and Labour in Latin America. Essays on the Development of Agrarian Capitalism in the Nineteenth and Twentieth Centuries, K. Duncan e I. Rut]edge (eds.) Cambridge. Cambridge University Press. 301-321.

Humboldt, A., 1956. Viaje a las Regiones Equinocciales del Nuevo Continente. Caracas, Minisțerio de Educación, 5 tomos. Pág. 85

IZARD, M., 1970. "Series Estadísticas para la Historia de Venezuela". Mérida. Universidad de los Andes. 
KRITZ, M., "Inmigration an Social Structure: The Venezuelan Case". Ph. D. Dissertation. University of Wisconsin.

LAMBERT, E., 1974. "Carabobo 1821". Caracas. Fundación John Boulton.

LASSER RE-Bigorry, J., 1975. "Panorama de las Principales Migraciones Internacionales Contemporáneas con Fines de Empleo". Ginebra. Oficina Internacional del Trabajo. Documento de Información No. 34.

LOMBARDI, J., 1974. "Decadencia y Abolición de la Esclavitud en Venezuela 1820-1854". Caracas. Universidad Central de Venezuela.

MÁRMORA, L., 1981. "Las Migraciones Laborales Internacionales en Venezuela" Quito. Multigrafiado.

Matrhews, R., 1977. "Violencia Rural en Venezuela, 1840-1858: Antecedentes Socioeconómicos de la Guerra Federal". Caracas. Editorial Monte Avila.

Presidencia de la República, 1970. "Mensajes Presidenciales". Caracas. Edjciores de la Presidencia. 5 tomos.

- 1977. "Mensaje Anual al Congreso Nacional Presentado por el Presidente de la República". Caracas. Ediciones de la Presidencia.

SASSEN-Koob, S., 1980. "Crecimiento Económico e Inmigración en Venezuela". Migraciones Internacionales en las Américas. 1, (1): 63-87.

Schloeter, M., Suárez, M. M., Torrealba, R., 1982. "Internacional Migration from Venezuela: The Case of SIDOR" en White Collar Migration in Latin America and the Caribbean, A. Marks y H. Vessuri (eds.). Leiden. Royal Institute of Linguistics and Anthropology. (En prensa)

Tennassee, P. N., 1979. "Venezuela, los Obreros Petroleros y la Lucha por la Democracia". Caracas. E.F.I. Publicaciones.

VANNINI, M., 1976. "Italia y los Italianos en la Historia y la Cultura de Venezuela" Caracas, Universidad Central de Venezuela.

- 1980. "Aportes de la Inmigración Italiana a la Venezuela Contemporánea" en Venezuela 1979: Examen y Futuro. Caracas. Editorial Ateneo de Caracas. 339-348.

VESSURI, H., 1982. "Scientific Inmigrants in Venezuela-Ethnicity, Nation and International Science" en White Collar Migration in Latin America and the Caribbean, A. Marks y H. Vessuri (eds.). Leiden. Royal Institute of Linguistics and Anthropology. (En prensa).

ZAWISZA, L., 1980. "Colonia Tovar, Tierra Venezolana". Caracas. Universidad Central de Venezuela. 